Journal of Animal \& Plant Sciences, 31(5): 2021, Page: 1427-1438

ISSN (print): 1018-7081; ISSN (online): 2309-8694

https://doi.org/10.36899/JAPS.2021.5.0344

\title{
ANTIMICROBIAL ACTIVITY AND COMPONENT ANALYSIS OF CLEOME SPINOSA AGAINST FUSARIUM OXYSPORUM
}

\author{
X. Z. Zhang ${ }^{1,2}$, C. L. Wang ${ }^{1}$, D. Liu ${ }^{1}$, R. N. Sa ${ }^{1,3}$, J. Y. Gao ${ }^{1}$, X. F. Liu ${ }^{1}$, D. W. Liu ${ }^{1}$, S. Yang ${ }^{1}$, T. Ma ${ }^{1}$, X. L. Li ${ }^{1}$, R. X. \\ $\mathrm{Chen}^{1}, \mathrm{H}$. R. Du ${ }^{1}$ and Y. J. Zhang ${ }^{1 *}$ \\ ${ }^{1}$ College of Agronomy, Northeast Agricultural University, Harbin, China; ${ }^{2}$ Mudanjiang Branch, Heilongiiang Academy \\ of Agricultural Science, Mudanjiang, China; ${ }^{3}$ Heilongjiang Academy of Agricultural Science, Harbin, China \\ ${ }^{*}$ Corresponding Author's E-mail: zhangyanju1968@163.com
}

\begin{abstract}
Cucumber Fusarium wilt is an important soil-borne disease that restricts cucumber production in all areas of the world. To explore the preventive effects of Cleome spinosa on cucumber Fusarium wilt, five different doses of Cleome spinosa powder including $0,0.1,0.2,0.3$, and $0.4 \mathrm{~g} /$ dish were applied to cucumber plant infected with Fusarium oxysporum f.sp. cucumarinum at Northeast Agricultural University. The data thus collected on various parameters were subjected to oneway analysis of variance (ANOVA) under Completely Randomized Design (CRD). The difference in treatment means were separated using Duncan's Multiple Range (DMR) Test. A 100\% inhibition rate on F. oxysporum mycelium was achieved when the dose of $C$. spinosa powder rose to 0.3 or $0.4 \mathrm{~g} /$ dish. As the concentration of the Cleome spinosa extract increased, the inhibitory effects on diameters and dry weight of mycelium also increased. Median inhibitory concentration of $C$. spinosa on mycelium was was $45.12 \mathrm{mg} \mathrm{mL}^{-1}$. Gas chromatography-mass spectrometry identified twenty-one sorts of volatile constituents of Cleome spinosa, including heterocyclic compounds, alcohol, chromene, ester, acid and long chain alkanes. Twelve components of $F$. oxysporum were extracted by fumigation. Among those components, paeonol, linalool and theaspirane had antimicrobial activities against $F$. oxysporum, with inhibition rates of $73.9 \%, 75.9 \%$ and $80.4 \%$, respectively. However, tetradecyl-oxirane, tetracosane, heptacosane, 3-ethyl-2-hydroxy-2cyclopenten-1-one, octacosane, 1,1,4A-trimethyl-3,4,4A,5,6,7-hexahydro-1H-naphthalen-2-one,6,10,14-trimethyl-2pentadecanone, methyl alpha-linolenate and pentatriacont-17-ene had no inhibitory effect against $F$. oxysporum. Those results suggested that the components of Cleome spinosa powder could effectively restrain cucumber Fusarium wilt.
\end{abstract}

Keywords: Antimicrobial activity, Cleome spinosa, Fusarium oxysporum, GC-MS, Volatile constituent identification Published first online January 24, 2021. Published final August 07, 2021.

\section{INTRODUCTION}

Cucumber (Cucumis sativus L.) represents a vital vegetable crop in the world, and with the continuous development of horticultural facilities, the planting acreage of cucumber has also increased (Zhang et al., 2012). Numerous abiotic and biotic variables lead to the low cucumber production, and amongst the biotic factors, Fusarium wilt is the most prominent and restricts the yield of cucumber in all regions worldwide (Raza et al., 2016). Fusarium wilt results from Fusarium oxysporum $\mathrm{f}$. sp. cucumarinum, one of the soil-borne plant pathogens that survive within soil for many years, and it is difficult to control ( $\mathrm{Li}$ et al., 2016). Agricultural, physical, biological and chemical treatments are the main measures of controlling soil-borne diseases. Among them, the use of chemical agents in soil disinfection and fumigation is effective for the prevention and control of cucumber Fusarium wilt; however, chemical agents not only pollute the soil but also cause great harm to human health (ElSharkawy et al., 2016). Therefore, a biological fumigant must be looked into that can be used as a substitute for chemical agents while posing no risk to the environment, humans and animals.

In recent years, biofumigation of Fusarium wilt has become a popular and environmentally friendly disease controlling strategy (Guo et al., 2018). Cruciferous brassica plants and a few other plants containing glucosinolates have been reported to have a biofumigation effect (Richard et al., 2001). Using biofumigation to control soil-borne pests can decrease the use of chemically synthesized pesticides, reduce pesticide residues, and help to prevent drug resistance and environmental pollution to achieve the goal of green plant soil-borne disorder and soil insect pest prevention and control. Biofumigation can effectively control some soilborne plant pathogens, reduce the use of chemical pesticides, increase crop yields, effectively improve the soil structure and increase the content of organic matter and beneficial microorganisms (Wang et al.,2014).

Cleome spinosa Jacq. (Capparaceae) is a herbaceous plant that is native to tropical regions in South America (Collins et al.,2004). Silva et al. (2016a) used chloroform, cyclohexane, methanol and ethyl acetate to extract microbial drug active substances based on Cleome spinosa roots and leaves and studied the 
antibacterial activity of the extracts against 17 kinds of human pathogenic bacteria, including bacteria and saccharomycetes. Sant'Anna investigated the antimicrobial capacity in vitro as well as the phytochemical compositions in Cleome spinosa Jacq leaf and root extracts when they were used to treat inflammation and infectious disease (Silva et al.,2016b). The antinociceptive and anti-inflammatory activities of methanol extracts obtained from Cleome spinosa plants growing in the natural regions, the acclimatized plants and those obtained from lipophilic mass that contains the beta-carotene acquired via callus cultures were assessed (Albarello et al., 2013). Cleome spinosa extracts are used in pharmaceutical preparations and cosmetic compositions and have antibacterial effects on some anthropic pathogenic fungi (Rene and Françoise, 2008).

Papadopoulos and Alderson (2010) used a gas chromatographic method to collect isothiocyanates with biofumigation activity from Cleome spinosa, and the isothiocyanate content was higher than that in the same quantity of Brassica crops. However, the preventive effects of Cleome spinosa on cucumber Fusarium wilt has not been reported.

This study aimed (1) to examine the antimicrobial activity and to identify antimicrobial substances of Cleome spinosa against Fusarium oxysporum, and (2) to explore the inhibition effect of Cleome spinosa on F. oxysporum f. sp. cucumarinum. This study will provide a new idea for the further use of biological fumigation to prevent soil-borne diseases.

\section{MATERIALS AND METHODS}

Materials and cultivation conditions of Cleome spinosa: Fusarium oxysporum f. sp. cucumerinum (FOC) was provided by the Plant Pathology Laboratory of the Northeast Agricultural University (Harbin, China). Cleome spinosa seeds were obtained from Beijing Fangxuanyuan Seed Co. Ltd.Cleome spinosa seeds were soaked in water at $25-30^{\circ} \mathrm{C}$ for 3 hours until the seeds swelled. The seeds were placed in a culture dish with filter paper soaked in $10 \% \mathrm{NaClO}$ solution. The culture dish was placed in a $30^{\circ} \mathrm{C}$ biological incubator for 3 to 5 days, and the seeds were watered daily until they sprouted. The seedlings were transplanted into a 1:1 sterilized soil and vermiculite mixture. After germination, the seedlings were removed from the incubator; this process took approximately 10-15 days. When the outdoor temperature exceeded $20^{\circ} \mathrm{C}$, Cleome spinosa seedlings were transplanted into the field at Northeast Agricultural University $\left(126^{\circ} 63^{\prime} \mathrm{E}, 45^{\circ} 44^{\prime} \mathrm{N}\right.$, Harbin, China) in May 28, 2017. The row spacing was $30 \mathrm{~cm}-45$ $\mathrm{cm}$. Plot size was $5 \mathrm{~m} \times 9 \mathrm{~m}$. There totally existed 20 plots. The plants were watered two times on each day. About three months later, stem and leaf samples were collected until the plant height reached 1 to 1.5 meters. The samples were dried and crushed into powder by a pulverizer. The research site is in the northern temperate zone and continental monsoon area (rainy and hot during the summer; cold and arid during the winter) and has an annual precipitation of 500 550 $\mathrm{mm}$ (Zhang et al., 2020). The average available accumulated temperature $\left(\geq 10^{\circ} \mathrm{C}\right)$ is $2709^{\circ} \mathrm{C}$. The characteristics of the experimental soil were $10.7 \%$ moisture, $35.7 \mathrm{~g} \mathrm{~kg}^{-1}$ organic matter, 176.3 $\mathrm{mg} \mathrm{kg}$ available nitrogen, $83.3 \mathrm{mg} \mathrm{kg} \mathrm{kg}^{-1}$ available phosphorus and $153.2 \mathrm{mg} \mathrm{kg}^{-1}$ available potassium (Zou et al., 2018).

Antimicrobial activity of Cleome spinosa against Fusarium oxysporum: The mycelial growth rate approach was applied in determining the Cleome spinosa antimicrobial activity against FOC (Yin et al., 2010). Fresh stems and leaves of Cleome spinosa (approximately 50 days old) were collected, cleaned and crushed into powder by a pulverizer. Fusarium oxysporum was cultured on PDA medium for 7 days, and were cut with a perforator (diameter $0.85 \mathrm{~cm}$ ) at the edge of the fungal colony. The fungi were inoculated in the center of PDA medium, and $0,0.1,0.2,0.3$, and 0.4 $\mathrm{g} /$ dish 5 different doses of Cleome spinosa powder were added to the culture dishes cover, which were sealed and placed in a $25^{\circ} \mathrm{C}$ incubator under dark conditions. Five technical replicates were performed for each experiment. The diameter of each colony was measured by the cross vertical measurement method every $24 \mathrm{~h}$, and the average value was determined. According to the measured results, the inhibition rate of Cleome spinosa against $F$. oxysporum was calculated.

Extraction of volatile oil from Cleome spinosa: The volatile substances of Cleome spinosa were obtained by steam distillation (Meng et al., 2014). Cleome spinosa stems and leaves $(50 \mathrm{~g})$ were crushed and placed in a flask containing $500 \mathrm{~mL}$ distilled water; after full mixing, $35 \mathrm{~g} \mathrm{NaCl}$ was added. A volatile oil extractor was connected to a reflux condensing tube, and distilled water was added to the upper end of the condensing tube to fill the calibrated part of the volatile oil tester, allowing overflow in a flask. Later, that flask was put into the electric heating sleeve, slowly heated to boiling, and then continuously boiled until the oil surface of the measuring device no longer changed. The piston was opened after one hour. The oil surface was reduced to the 0 scale, and the volatile oil was dissolved in ethyl acetate.

Preparation of Cleome spinosa extracts: The mycelial growth rate method was applied in determining Cleome spinosa extracts'mycelial inhibition activities against Fusarium oxysporum mycelium (Yin et al., 2010). The stems and leaves of Cleome spinosa were dried, smashed, and sieved (40 mesh screen) and then weighed to exactly 100 grams. The sample was mechanically mixed with 
$500 \mathrm{~mL}$ of ethyl acetate solvent and then extracted at a constant temperature $\left(30^{\circ} \mathrm{C}, 150 \mathrm{r} / \mathrm{min}\right)$ for 5 days. The mixture was filtered using the filter paper (3 layers) was used to filter the mixture, followed by $5 \mathrm{~min}$ of centrifugation at $5000 \mathrm{rpm}$ to collect supernatants. The supernatants were poured into the rotary evaporator $\left(45^{\circ} \mathrm{C}\right)$, concentrated to a thick paste, and then transferred to the volumetric flask $(100 \mathrm{~mL})$. Then, $20 \%$ ethanol was used to fix the volume to $100 \mathrm{ml}$ at a concentration of 1 $\mathrm{g} / \mathrm{mL}$. The solution was vernalized in a refrigerator at $4^{\circ} \mathrm{C}$. For the bioassay, sterile dimethyl sulfoxide at a fraction volume of $1 \%$ (10\% DMSO aqueous solution) was added to the extract and then five experimental concentrations at 5, 15, 30, 45 and $60 \mathrm{mg} / \mathrm{ml}$ were synthesized with sterile water in the same amount as the control, with 5 repetitions. All extracts and sterile water were used under strict aseptic operations.

In the $90 \mathrm{~mL}$ PDA medium with high pressure sterilization, $10 \mathrm{~mL}$ of different concentrations of the Cleome spinosa extracts was added, mixed and spread onto 5 Petri dishes of $9 \mathrm{~cm}$ diameter. The PDA medium was prepared for each treatment concentration 5 times.

Inhibition activity of Cleome spinosa extracts on mycelium growth of Fusarium oxysporium: A $6 \mathrm{~mm}$ diameter puncher was used to cut the Cucumber Fusarium colony that had been cultivated for 7 days within the PDA medium from the edge of the colony. Then, the fungal cake should be inoculated into the petri dish center under Cleome spinosa extract treatment and inoculated into the control petri dish center. Afterwards, the sealing membrane was used to seal the dish, followed by transfer in to the incubator under the temperature of $30^{\circ} \mathrm{C}$ with the cap facing down.

The cross vertical measurement method was used to investigate and record the analysis. The growth control group pathogen mycelial growth conditions were measured to determine the diameter of each colony via the cross vertical measurement method every $24 \mathrm{~h}$, and the average value was determined. According to the measured results, the inhibiting rate of Cleome spinosa extracts on Fusarium oxysporum mycelial growth was calculated. Meanwhile, the inhibiting activity of extracts of Cleome spinosa on Fusarium oxysporum mycelial growth was evaluated. The lethal concentration $\left(\mathrm{EC}_{50}\right)$ of the mycelial growth and the virulence regression equation were calculated based on the Cleome spinosa extracts.

Net growth=Average colony diameter-control diameter. The inhibition ratio was calculated by the following formula, [(mean control colony diameter mean treatment colony diameter)/mean control colony diameter] $\times 100 \%$.

Influences of Cleome spinosa extracts at diverse contents on the Fusarium oxysporum. mycelial dry weight: The mycelium dry weight was determined by the liquid culture method (Krakowska et al., 2016). A $3 \mathrm{~mm}$ diameter puncher was used to cut the cucumber Fusarium colony that had been cultured on PDA medium for 5 days from the edge of the colony. Then, taking 6 pieces of the fungal cake with the inoculator. Adding $250 \mathrm{~mL}$ extract of Cleome spinosa to a triangular flask containing different concentrations of the extract and the control medium, respectively. And sealing with sealing membrane. The culture time was 5 days under a constanttemperature shaking table $\left(30^{\circ} \mathrm{C}, 120 \mathrm{r} / \mathrm{min}\right)$. The cultured solution was centrifuged with a $4000 \mathrm{r} / \mathrm{min}$ centrifuge and filtered. The filter was wrapped in filter paper and placed in a $65^{\circ} \mathrm{C}$ oven and dried to a constant weight. The weight of the dried hyphae and filter paper was weighed using a scale of 1:10000. The lethal weight $\left(\mathrm{EC}_{50}\right)$ of the mycelial dry weight and the virulence regression equation were calculated by Cleome spinosa extracts. The mycelial dry weight=Total dry substance weight-dry weight of filter paper. The inhibition ratio was calculated by the formula below: [(mean control mycelial dry weight- mean treatment mycelial dry weight)/mean control mycelial dry weight] $\times 100 \%$.

Effect of Cleome spinosa extracts on mycelial morphology: Influences of Cleome spinosa extracts at diverse contents were determined according to Fusarium oxysporum mycelial dry weight. The medium $\left(\mathrm{EC}_{50}\right)$ of the Cleome spinosa extract, which inhibited mycelium, was a treatment group, and the medium containing an equal amount of water was a control group.

The cultured solution was centrifuged with a $4000 \mathrm{r} / \mathrm{min}$ centrifuge and filtered. Then, the complete hypha was removed for experimental observations of the hyphal morphology by scanning electron microscopy (Spanggaard et al.,2006). The sample was sliced to small strips $(2 \mathrm{~mm} * 5 \mathrm{~mm})$ that had a double-sided blade. The sample was fixed with glutaraldehyde $(2.5 \%, \mathrm{pH} 6.8)$ for $1.5 \mathrm{~h}$. Then, the sample was stored in a $4^{\circ} \mathrm{C}$ refrigerator. Subsequently, it was rinsed with $0.1 \mathrm{~mol} \mathrm{pH} 6.8$ phosphate buffer three times for $10 \mathrm{~min}$ each time. Dehydration was carried out with $50 \%, 70 \%$ and $90 \%$ ethanol for $15 \mathrm{~min}$ each time and then with a mixture (tert-butanol: $100 \%$ ethanol, $1: 1$ ) as well as pure tertbutanol once for $15 \mathrm{~min}$ each time. Later, all samples were preserved within the $-20^{\circ} \mathrm{C}$ refrigerator for $30 \mathrm{~min}$, and then the samples were dried off with the ES-2030 freeze dryer (Hitachi, Janpan) for $4 \mathrm{~h}$. Conductive tape was used to adhere the sample to the scanning electron microscope table to ensure that the samples were observed face up. The surface of the sample was plated with a metal film using an E-1010 type ion sputtering coating instrument (Coxem, Korea). Observations and stereos can photograph were taken with the scanning electron microscope.

Analysis of volatile substances from Cleome spinosa: The volatile substances were extracted from Cleome spinosa through gas chromatography-mass spectrometry 
(GC/MS) analysis (Zhang etal.,2015) as follows: theBD$5 \mathrm{MS}$ elastic quartz capillary column was used (dimension, $30 \mathrm{~m} \times 0.25 \mathrm{~mm} \times 0.25 \mu \mathrm{m}$ ) with sample inlet temperature of $250^{\circ} \mathrm{C}$. Meanwhile, ECD detector temperature was $250^{\circ} \mathrm{C}$. High-purity helium $(>99.999 \%)$ was used as the carrier gas at the flow rate of $1 \mathrm{~mL} / \mathrm{min}$; the column temperature started at $45^{\circ} \mathrm{C}$ for a period of 5 min, which increased to $210^{\circ} \mathrm{Cand}$ maintained for $3 \mathrm{~min}$ and then to $230^{\circ} \mathrm{C}$; and then $1 \mu \mathrm{L}$ injection volume was applied using the splitless injection. The MS conditions were as follows: ionization temperature at $230^{\circ} \mathrm{C}$, electronic energy $60 \mathrm{eV}$, emission current $35 \mu \mathrm{A}$, quadrupole rod temperature $165^{\circ} \mathrm{C}$, temperature of transfer interface at $275^{\circ} \mathrm{C}$, voltage of electronic multiplier at $350 \mathrm{~V}$, range of mass scanning of 45-500 amu. The components obtained by the NIST 05 standard mass spectrometry library were analyzed.

Antimicrobial activity of volatile substances of Cleome spinosa against Fusarium oxysporum: The volatile substances of Cleome spinosa were determined by GC/MS experiments, and 21 components were obtained. The antimicrobial activity of 12 volatile substances against Fusarium oxysporum was tested by the mycelial growth rate method. These substances were paeonol, linalool, tetradecyl-oxirane, tetracosane, heptacosane, 3ethyl-2-hydroxy-2-cyclopenten-1-one, octacosane, theaspirane, 1,1,4A-trimethyl-3,4,4A,5,6,7-hexahydro1H-naphthalen-2-one,

pentadecanone, methyl alpha-linolenate, and pentatriacont-17-ene.

Fusarium oxysporum was cultivated for 7 days within the PDA medium, and fungi were cut with a perforator (diameter $0.85 \mathrm{~cm}$ ) at the edge of the fungal colony. The fungi were inoculated in the center of PDA medium, and a certain amount of the twelve substances mentioned above was added to the $9 \mathrm{~cm}$ Petri dish, which was placed in a $25^{\circ} \mathrm{C}$ incubator under dark conditions. Five technical replicates were performed for each substance. The diameter of each colony was measured by the cross vertical measurement method every $24 \mathrm{~h}$, and the average value was calculated. The fumigation effects of the twelve substances on Fusarium oxysporum were calculated according to the measured results. According to three volatile substances (theaspirane, paeonol and linalool) that accounted for a percentage of the 21 volatile substances obtained in the GC/MS experiment, antimicrobial experimental designs were carried out with dosages of $0,100 \%, 200 \%, 300 \%$ and $400 \%$ of the 3 substances contained in $0.3 \mathrm{~g}$ Cleome spinosa. The contents of the 3 substances in each Petri dish were as follows: theaspirane: $0 \mathrm{~g} / \mathrm{dish}, 0.00753 \mathrm{~g} / \mathrm{dish}, 0.01506$ $\mathrm{g} /$ dish, $0.02259 \mathrm{~g} / \mathrm{dish}, 0.03012 \mathrm{~g} / \mathrm{dish}$; paeonol: $0 \mathrm{~g} / \mathrm{dish}$, $0.0678 \mathrm{~g} / \mathrm{dish}, 0.1356 \mathrm{~g} / \mathrm{dish}, 0.2034 \mathrm{~g} / \mathrm{dish}, 0.2712$ $\mathrm{g} /$ dish; linalool: $0 \mathrm{~g} / \mathrm{dish}, 0.01122 \mathrm{~g} / \mathrm{dish}, 0.02244 \mathrm{~g} / \mathrm{dish}$,
$0.03366 \mathrm{~g} / \mathrm{dish}, \quad 0.04488 \mathrm{~g} / \mathrm{dish}$. The method of investigation was the same as that specified above.

Five technical replicates were performed for each experiment. The data thus collected on various parameters were subjected to one-way analysis of variance (ANOVA) under Completely Randomized Design (CRD) through SPSS 20.0 (IBM, New York, USA). The difference in treatment means were separated using Duncan's Multiple Range (DMR) Test (Duncan, 1955).

\section{RESULTS}

Antimicrobial effect of Cleome spinosa on Fusarium oxysporum: Four doses of Cleome spinosa had inhibitory effects on Fusarium oxysporum (Fig. 1 \& 2). The average growth diameter of the control (CK) was $2.917 \mathrm{~cm}$. The average growth diameter of the colony was $1.986 \mathrm{~cm}$, and the inhibition rate was $32.2 \%$ after the fumigation treatment consisting of $0.1 \mathrm{~g}$ of pulverized Cleome spinosa material compared with $54.8 \%$ for a colony of $1.313 \mathrm{~cm}$, respectively, in response to $0.2 \mathrm{~g}$ of pulverized material $(0.2 \mathrm{~g})$. In the 0.3 and $0.4 \mathrm{~g}$ treatments, the average growth diameter of the colony was $0 \mathrm{~cm}$ and the antimicrobial rate was $100 \%$.

Inhibition activity of Cleome spinosa extracts on mycelium growth of Fusarium oxysporium: As the concentration of Cleome spinosa extract increased, the inhibition of mycelium also increased. The colony diameter of control group was $66.85 \mathrm{~mm}$. The diameters of Fusarium oxysporum were $56.55 \mathrm{~mm}, 50.46 \mathrm{~mm}$, $41.86 \mathrm{~mm}, 31.85 \mathrm{~mm}$ and $27.28 \mathrm{~mm}$ when the concentrations of Cleome spinosa extracts was 5, 15, 30, 45 as well as $60 \mathrm{mg} / \mathrm{mL}$, respectively (Table 1).

Influences of Cleome spinosa extracts at diverse contents on Fusarium oxysporium mycelial dry weight: the notable inhibition of Cleome spinosa extracts at diverse contents on the accumulation of Fusarium oxysporium mycelial dry substances (Fig. 3). As Cleome spinosa extract contents increased, the inhibitory effects also increased. For the control, its weight of mycelial dry substances was $1.606 \mathrm{~g}$. When the concentration of the Cleome spinosa extracts was $5,15,30,45$ and $60 \mathrm{mg} / \mathrm{mL}$, while the Fusarium oxysporum mycelium dry substance accumulation was $0.945,0.328,0.198,0.098$ and $0.019 \mathrm{~g}$, separately. The low concentrations of Cleome spinosa extracts had a low inhibition rate on the dry substance accumulation of Fusarium oxysporium. When the concentration was $5 \mathrm{mg} / \mathrm{mL}$, the inhibition rate of mycelium was only $41.16 \%$. When the concentration of the Cleome spinosa extracts was 15,30, 45 and 60 $\mathrm{mg} / \mathrm{mL}$, with the mycelial dry substance accumulation inhibition ratios of $79.58 \%, 87.67 \%, 93.90 \%$ and $98.82 \%$, respectively. The inhibitory medium concentration of mycelial dry substance accumulation $\left(\mathrm{EC}_{50}\right)$ was 6.57 
$\mathrm{mg} / \mathrm{mL}$ and the regression equation of virulence was $\mathrm{Y}=2.080 \mathrm{x}+3.292$ (Table 2). Moreover, the weight of

mycelial dry substances showed clear negative correlation with Cleome spinosa extracts concentration.

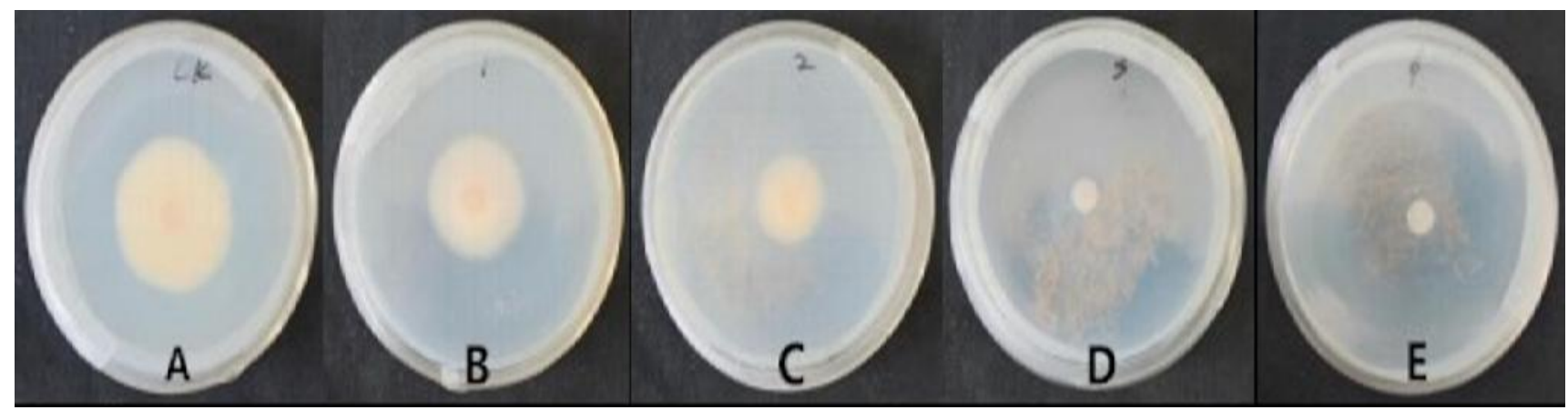

Fig. 1 Antimicrobial effect of different doses of Cleome spinosa against Fusarium oxysporum A: CK, B: 0.1, C: 0.2, D: 0.3, and E: 0.4 g/dish.

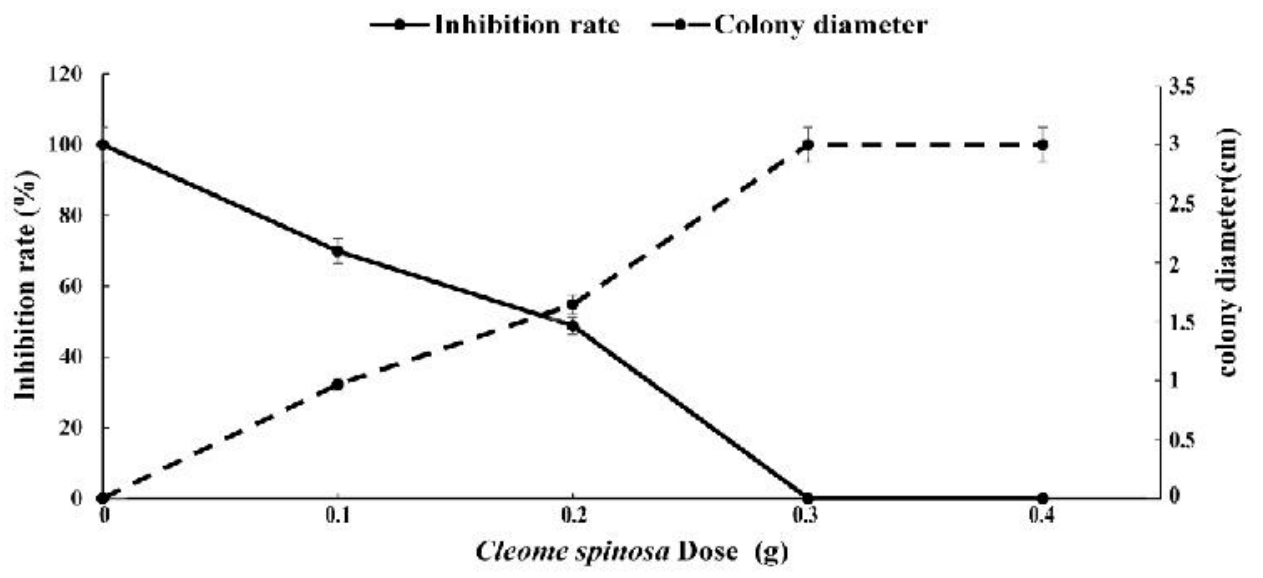

Fig. 2 Antimicrobial effect of different doses of Cleome spinosa against Fusarium oxysporum

Table 1: Inhibition activity of Cleome spinosa extractsat diverse content on the mycelial growth.

\begin{tabular}{cccccc}
\hline $\begin{array}{c}\text { Concentration } \\
(\mathbf{m g} / \mathbf{m L})\end{array}$ & $\begin{array}{c}\text { Logarithm of } \\
\text { concentration }(\mathbf{X})\end{array}$ & $\begin{array}{c}\text { Diameter of colony } \\
(\mathbf{m m})\end{array}$ & $\begin{array}{c}\text { Inhibition rate } \\
(\mathbf{\%})\end{array}$ & $\begin{array}{c}\text { Probit } \\
(\mathbf{y})\end{array}$ & $\begin{array}{c}\text { Toxicity regression } \\
\text { curve }(\mathbf{y}=)\end{array}$ \\
\hline 5 & 0.699 & $56.55 \mathrm{~b}$ & 15.41 & 3.9812 & $\mathrm{y}=1.169 \mathrm{x}+3.066$ \\
15 & 1.176 & $50.46 \mathrm{c}$ & 24.52 & 4.3114 & $\mathrm{R}^{2}=0.952$ \\
30 & 1.477 & $41.86 \mathrm{~d}$ & 37.38 & 4.6780 & $\mathrm{EC}_{50}=45.12 \mathrm{mg} / \mathrm{mL}$ \\
45 & 1.653 & $31.85 \mathrm{e}$ & 52.36 & 5.0596 & \\
60 & 1.778 & $27.28 \mathrm{f}$ & 59.19 & 5.2326 & \\
CK & & $66.85 \mathrm{a}$ & & & \\
\hline
\end{tabular}

Different lowercase letters indicate significant differences at the 0.05 level $(\mathrm{P}<0.05)$.

Effect of Cleome spinosa extracts on mycelial morphology: The surface of the mycelium of Fusarium oxysporum was smooth and complete under a $3.00 \mathrm{~K}$ fold scanning electron microscope (Fig. 4A). At $3.00 \mathrm{~K}$ fold, a wrinkled phenomenon was observed on the surface of the Fusarium oxysporum mycelium, some of which were shriveled and folded (Fig. 4B). The rapid and lower growth of mycelium on PDA medium magnified at 750 times in the control and experiment groups (Fig. 4 C, D). The mycelium treated with Cleome spinosa extracts showed uneven thickness and a lower quantity.
Analysis of volatile substances from Cleome spinosa: A total of 21 compounds were isolated by GC/MS and identified using the NIST 05 standard mass spectrometry library-computer online search (Fig. 5 and Table 3). The 21 substances included heterocyclic rings, alcohol, chromene, ester, acid and long chain alkanes. The most abundant substance detected was paeonol $(22.60 \%)$, followed by1,1,4a-trimethyl-3,4,4a,5,6,7-hexahydro$2(1 \mathrm{H})$-naphthalenone $\quad(12.56 \%), \quad 2,5,5,8 \mathrm{a}$-tetramethyl3,4,4a,5,6,8a-hexahydro-2H-chromene( $8.00 \%), 9,12,15-$ 
octadecatrienal (6.78\%) n-hexadecanoic acid (5.04\%), linalool (3.74\%), 3-ethyl-5-(2-ethylbutyl)-octadecane (3.46\%), 6,10,14-trimethyl-2-pentadecanone (3.29\%), tetradecyl-oxirane $\quad(3.19 \%), \quad 9$-hexyl-heptadecane $(3.17 \%)$, 17-pentatriacontene $\quad(3.16 \%)$, tetracosane (3.13\%), 7-hydroxy-7,8,9,10-tetramethyl-2, 8dihydrocyclohepta[d,e]-naphthalene $\quad(3.10 \%), \quad 7,12 \mathrm{a}-$ dimethyl-1,2,3,4,4a,11,12, 12a- octahydrochrysene $\mathbf{( 2 . 9 3 \% ) , ~ h e p t a c o s a n e}(2.89 \%)$, 3-ethyl-2-hydroxy-2cyclopenten-1-one $(2.69 \%)$, octacosane $\quad(2.09 \%)$, 2,6,10,10-tetramethyl-1-oxaspiro[4.5]dec-6-ene (2.51\%), gephyrotoxin 207a(1.95\%), 2,6-dimethyl-1-cyclohexen1 -ol-acetate (1.92\%), and 4-hydroxy- $\beta$-ionone (1.81\%).

Antimicrobial activity of volatile substances of Cleome spinosa against Fusarium oxysporum: The antimicrobial effect of 12 types of Cleome spinosa volatile substances $(0.3 \mathrm{~g} / \mathrm{dish})$ on Fusarium oxysporum was shown in Fig. 6. Theaspirane, linalool and paeonol had inhibitory effects on Fusarium oxysporum. However, tetradecyl-oxirane, tetradecane, heptadecane, octadecane, 3-ethyl-2-hydroxy-2-Cyclopenten-1-one, 1,1,4Atrimethyl-3,4,4A,5,6,7-hexahydro-1H-naphthalen-2-one, 6,10,14-trimethyl-2-pentadecanone pentatriacont-17-ene, methyl alpha-linolenate had no antimicrobial activity.

The inhibitory effects of different doses of theaspirane, linalool and paeonol on Fusarium oxysporum were further studied. As the dose per dish of the three substances increased, the inhibition rate increased (Fig. $7 \& 8$ ). The dosages of theaspirane were $0.00753 \mathrm{~g} / \mathrm{dish}, 0.01506 \mathrm{~g} / \mathrm{dish}, 0.02259 \mathrm{~g} / \mathrm{dish}$, and $0.03012 \mathrm{~g} / \mathrm{dish}$, resulting in respective inhibition rates of $45.2 \%, 70.1 \%, 70.0 \%$ and $73.8 \%$. The dosages of paeonol were $0.0678 \mathrm{~g} / \mathrm{dish}, 0.1356 \mathrm{~g} / \mathrm{dish}, 0.2034 \mathrm{~g} / \mathrm{dish}$, and $0.2712 \mathrm{~g} / \mathrm{dish}$, resulting in respective inhibition rates of $70.9 \%, 78.1 \%, 79.7 \%$ and $75.9 \%$. The dosages of linalool were $0.01122 \mathrm{~g} / \mathrm{dish}, 0.02244 \mathrm{~g} / \mathrm{dish}, 0.03366$ $\mathrm{g} / \mathrm{dish}$, and $0.04488 \mathrm{~g} / \mathrm{dish}$, resulting in respective inhibition rates of $55.1 \%, 60.4 \%, 74.0 \%$ and $80.4 \%$.

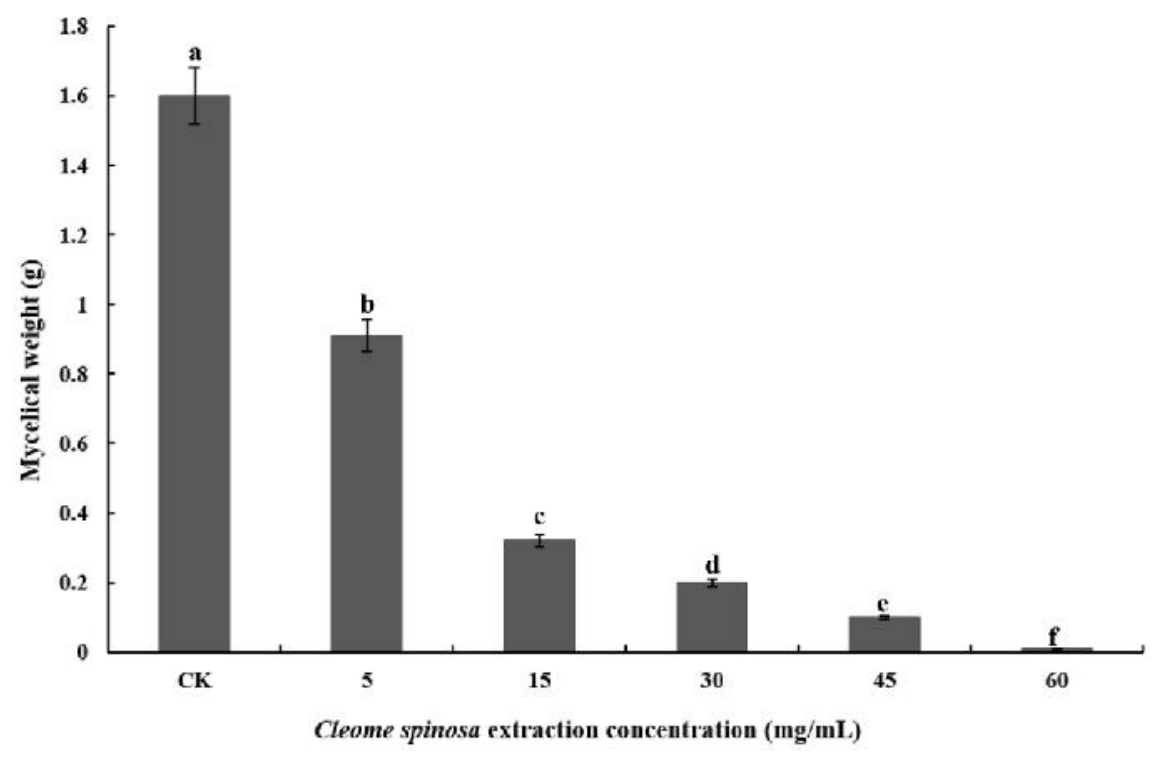

Fig. 3 Inhibition activity of Cleome spinosa extracts at diverse contents on the weight of mycelial dry substances.

Table 2: Inhibition activity of Cleome spinosa extracts at diverse contents on the weight of mycelial dry substances.

\begin{tabular}{cccccc}
\hline $\begin{array}{c}\text { Concentration } \\
(\mathbf{m g} / \mathbf{m} / \mathbf{L})\end{array}$ & $\begin{array}{c}\text { Logarithm of } \\
\text { concentration }(\mathbf{X})\end{array}$ & $\begin{array}{c}\text { Mycelium } \\
\text { weight }(\mathbf{g})\end{array}$ & $\begin{array}{c}\text { Inhibition } \\
\text { rate } \mathbf{( \% )}\end{array}$ & $\begin{array}{c}\text { Probit } \\
(\mathbf{y})\end{array}$ & $\begin{array}{c}\text { Toxicity regression } \\
\text { curve }(\mathbf{y}=)\end{array}$ \\
\hline 5 & 0.699 & $0.945 \mathrm{~b}$ & 41.16 & $4.7760 a$ & $\mathrm{Y}=2.080 \mathrm{x}+3.292$ \\
15 & 1.176 & $0.328 \mathrm{c}$ & 79.58 & 5.8268 & $\mathrm{R}^{2}=0.953$ \\
30 & 1.477 & $0.198 \mathrm{~d}$ & 87.67 & 6.1582 & $\mathrm{EC}_{50}=6.57 \mathrm{mg} / \mathrm{mL}$ \\
45 & 1.653 & $0.098 \mathrm{e}$ & 93.90 & 6.5464 & \\
60 & 1.778 & $0.019 \mathrm{f}$ & 98.82 & 7.2636 & \\
CK & & $1.606 \mathrm{a}$ & & & \\
\hline
\end{tabular}

Different lowercase letters indicate significant differences at the 0.05 level $(\mathrm{P}<0.05)$. 

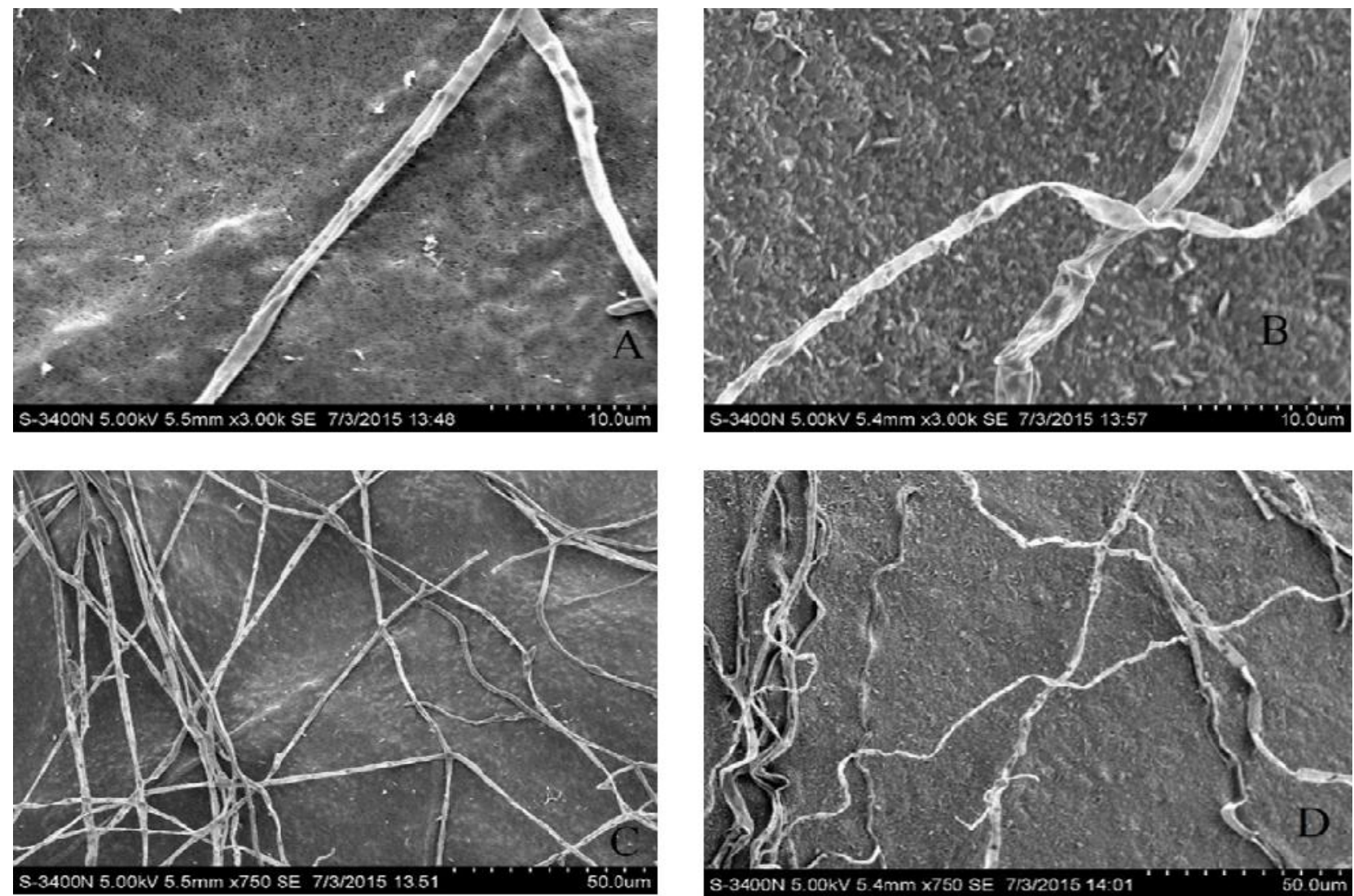

Fig. 4 Scanning electron microscope observations of mycelium A: Observation of the control mycelium at 3.00 $\mathrm{K} \times$; B: Observation of the mycelium treated with $45 \mathrm{mg} / \mathrm{mL}$ Cleome spinosa extract at $3.00 \mathrm{~K} \times$; $\mathrm{C}$ : Observation of the control mycelium at 750×; D: Observation of the mycelium treated with $45 \mathrm{mg} / \mathrm{mL}$ Cleome spinosa extract at $750 \times$

Table 3 Volatile substances extracted from Cleome spinose.

\begin{tabular}{|c|c|c|c|c|c|}
\hline No. & $\begin{array}{c}\text { Retention } \\
\text { time/min }\end{array}$ & Chemical compound & $\begin{array}{c}\text { Molecular } \\
\text { formula }\end{array}$ & $\begin{array}{c}\text { Molecular } \\
\text { weight }\end{array}$ & $\begin{array}{l}\text { Relative } \\
\text { content }\end{array}$ \\
\hline 1 & 5.80 & Linalool & $\mathrm{C}_{10} \mathrm{H}_{18} \mathrm{O}$ & 154 & 3.74 \\
\hline 2 & 8.38 & 1,1,4A-trimethyl-3,4,4A,5,6,7-hexahydro-1H-haphthalen-2-one & $\mathrm{C}_{13} \mathrm{H}_{20} \mathrm{O}$ & 192 & 12.56 \\
\hline 3 & 8.53 & 2,5,5,8a-tetramethyl-3,4,4a,5,6,8a-hexahydro-2H-chromene & $\mathrm{C}_{13} \mathrm{H}_{22} \mathrm{O}$ & 194 & 8.00 \\
\hline 4 & 8.67 & Theaspirane & $\mathrm{C}_{13} \mathrm{H}_{22} \mathrm{O}$ & 194 & 2.51 \\
\hline 5 & 8.86 & Gephyrotoxin $207 \mathrm{a}$ & $\mathrm{C}_{14} \mathrm{H}_{25} \mathrm{~N}$ & 207 & 1.95 \\
\hline 6 & 10.08 & Paeonol & $\mathrm{C}_{8} \mathrm{H}_{10} \mathrm{O}_{3}$ & 154 & 22.60 \\
\hline 7 & 10.29 & 4-hydroxy- $\beta$-ionone & $\mathrm{C}_{13} \mathrm{H}_{20} \mathrm{O}_{2}$ & 208 & 1.81 \\
\hline 8 & 10.37 & 3-ethyl-2-hydroxy-2-cyclopenten-1-one & $\mathrm{C}_{7} \mathrm{H}_{10} \mathrm{O}_{2}$ & 126 & 2.69 \\
\hline 9 & 10.54 & 2,6-dimethyl-1-cyclohexen-1-ol-acetate & $\mathrm{C}_{10} \mathrm{H}_{16} \mathrm{O}_{2}$ & 168 & 1.92 \\
\hline 10 & 13.51 & tetradecyl-oxirane & $\mathrm{C}_{10} \mathrm{H}_{32} \mathrm{O}_{2}$ & 184 & 3.19 \\
\hline 11 & 14.93 & 6,10,14-trimethyl-2-pentadecanone & $\mathrm{C}_{18} \mathrm{H}_{36} \mathrm{O}$ & 268 & 3.29 \\
\hline 12 & 15.32 & Methyl linolenate & $\mathrm{C}_{18} \mathrm{H}_{3} \mathrm{OO}_{2}$ & 262 & 6.78 \\
\hline 13 & 16.06 & n-Hexadecanoic acid & $\mathrm{C}_{16} \mathrm{H}_{32} \mathrm{O}_{2}$ & 220 & 5.04 \\
\hline 14 & 17.53 & Octacosane & $\mathrm{C}_{28} \mathrm{H}_{58}$ & 394 & 2.09 \\
\hline 15 & 18.40 & 17-pentatriacontene & $\mathrm{C}_{35} \mathrm{H}_{70}$ & 490 & 3.16 \\
\hline 16 & 19.26 & Tetracosane & $\mathrm{C}_{24} \mathrm{H}_{50}$ & 338 & 3.13 \\
\hline 17 & 20.20 & 9-hexyl-heptadecane & $\mathrm{C}_{23} \mathrm{H}_{48}$ & 324 & 3.17 \\
\hline 18 & 21.31 & Heptacosane & $\mathrm{C}_{17} \mathrm{H}_{36}$ & 240 & 2.89 \\
\hline 19 & 22.66 & 7,12a-Dimethyl-1,2,3,4,4a,11,12, 12a-octahydrochrysene & $\mathrm{C}_{18} \mathrm{H}_{24}$ & 240 & 2.93 \\
\hline 20 & 24.34 & 3-ethyl-5-(2-ethylbutyl)-octadecane & $\mathrm{C}_{26} \mathrm{H}_{54}$ & 366 & 3.46 \\
\hline 21 & 26.44 & $\begin{array}{l}\text { 7-Hydroxy-7,8,9,10-tetramethyl-7,8-dihydrocyclohepta[d,e]- } \\
\text { naphthalene }\end{array}$ & $\mathrm{C}_{18} \mathrm{H}_{20} \mathrm{O}$ & 252 & 3.10 \\
\hline
\end{tabular}




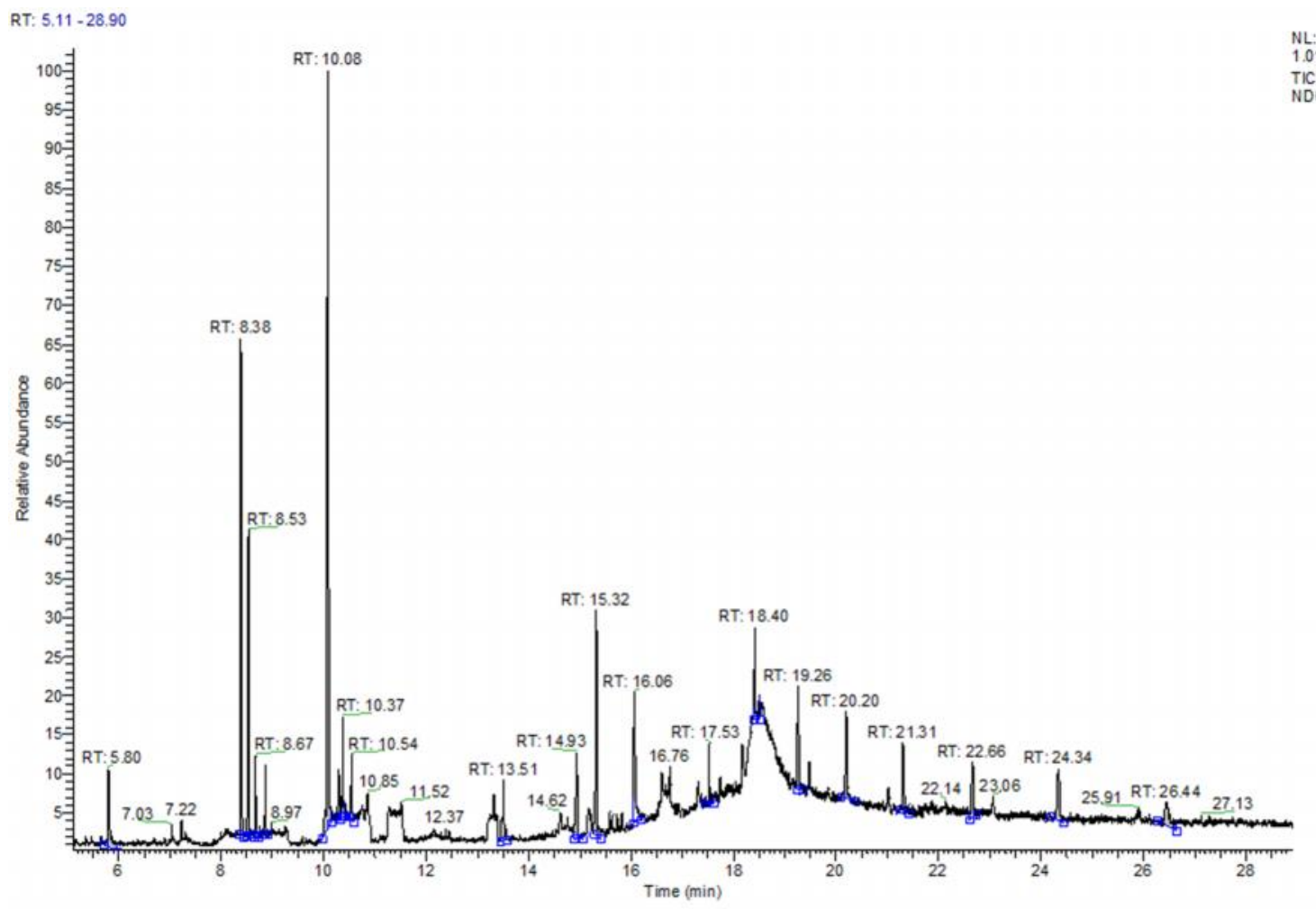

Fig. $5 \mathrm{GC} / \mathrm{MS}$ total ion chromatogram of Cleome spinose

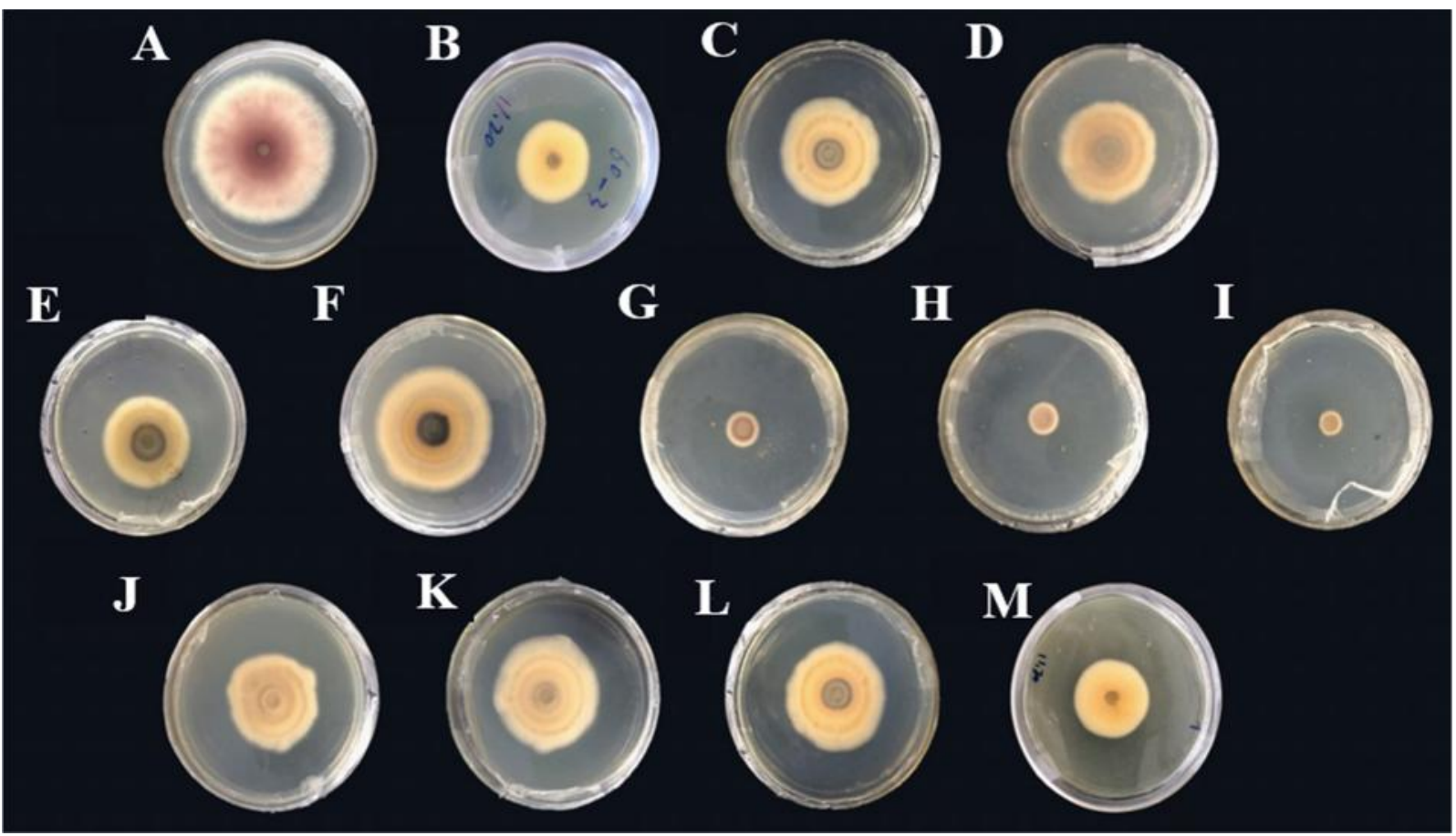

Fig. 6: Antibacterial effect of eight types of Cleome spinosa volatile substances on Fusarium oxysporum A : CK, B: Tetradecyl-oxirane, C: Tetradecane, D: Heptadecane, E: Octadecane, F: 3-ethyl-2-hydroxy-2cyclopenten-1-one, G: Theaspirane, H: Linalool, I: Paeonol, J: 1,1,4A-trimethyl-3,4,4A,5,6,7-hexahydro1H-naphthalen-2-one, K: 6,10,14-trimethyl-2-pentade canone, L: Pentatriacont-17-ene, and M: Methyl alpha-linolenate. 


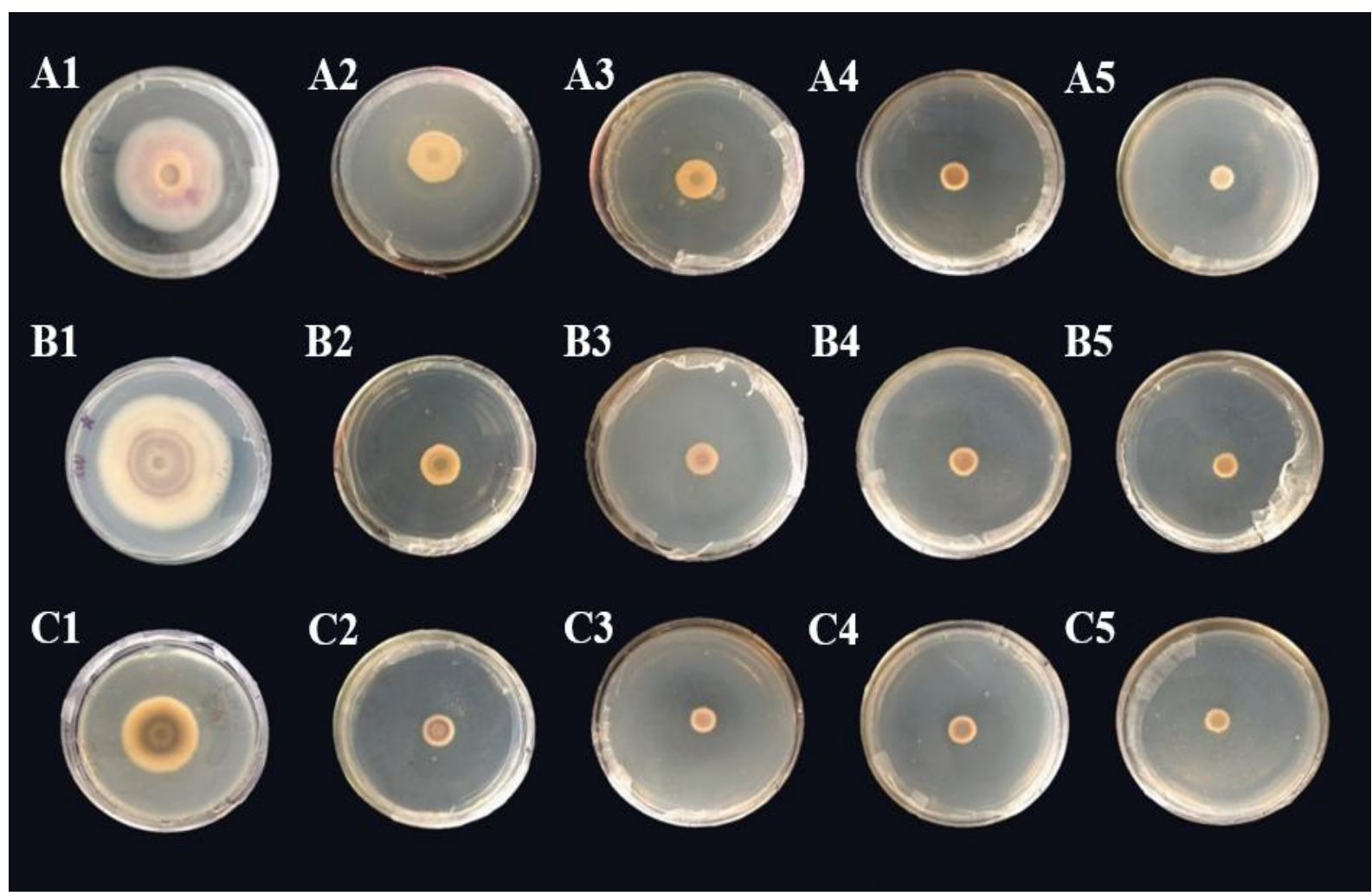

Fig.7: Antimicrobial effect of theaspirane, linalool and paeonol on Fusarium oxysporum A: Antimicrobial effect of theaspirane on cucumber Fusarium wilt. A1: CK, A2: 0.00753 g/dish, A3: 0.01506 g/dish, A4: 0.02259 g/dish, A5: $0.03012 \mathrm{~g} / \mathrm{dish}$; B: Antimicrobial effect of paeonol on cucumber Fusarium wilt. B1: CK, B2: $0.0678 \mathrm{~g} / \mathrm{dish}, \mathrm{B3}$ : 0.1356 g/dish, B4: 0.2034 g/dish, B5: 0.2712 g/dish; C: Antimicrobial effect of linalool on cucumber Fusarium wilt. C1: CK, C2: 0.01122 g/dish, C3: 0.02244 g/dish, C4: 0.03366 g per dish, C5: $0.04488 \mathrm{~g} / \mathrm{dish}$.

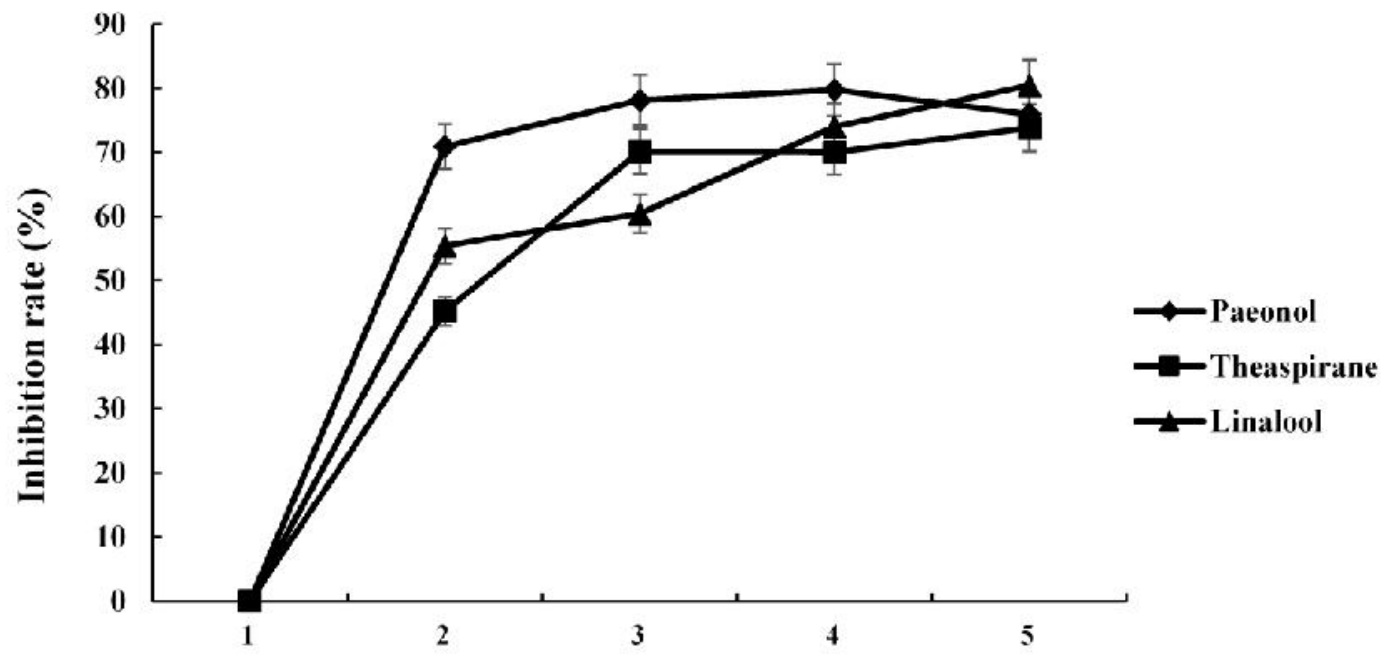

Cleome spinosa Dose (g)

Fig. 8: Inhibitory effect of different doses of theaspirane, linalool and paeonol on Fusarium oxysporum. The doses of theaspirane were $0 \mathrm{~g} / \mathrm{dish}, 0.00753 \mathrm{~g} / \mathrm{dish}, 0.01506 \mathrm{~g} / \mathrm{dish}, 0.02259 \mathrm{~g} / \mathrm{dish}$, and $0.03012 \mathrm{~g} / \mathrm{dish}$. The doses of paeonol were $0 \mathrm{~g} / \mathrm{dish}, 0.0678 \mathrm{~g} / \mathrm{dish}, 0.1356 \mathrm{~g} / \mathrm{dish}, 0.2034 \mathrm{~g} / \mathrm{dish}$, and $0.2712 \mathrm{~g} / \mathrm{dish}$. The doses of linalool were $0 \mathrm{~g} / \mathrm{dish}, 0.01122 \mathrm{~g} / \mathrm{dish}, 0.02244 \mathrm{~g} / \mathrm{dish}, 0.03366 \mathrm{~g} / \mathrm{dish}$, and $0.04488 \mathrm{~g} / \mathrm{dish}$. 


\section{DISCUSSION}

Biological fumigation uses biologically volatile gas that is produced via organic compound decomposition from Cruciferae or other plants to restrain or kill the hazardous soil organisms (Henderson et al., 2009). Cruciferous plants, especially Brassica plants, have biological fumigation potential (Motisi et al., 2013). Soil fumigation with mustard, cabbage and turnip has been used to inhibit many soil-borne pathogens, such as Fusarium (Sun et al., 2015), Rhizoctonia solani (Mercier and Jiménez, 2009), Verticillium dahliae (Njoroge et al.,2008), Aphanomyces euteiches (Szczygłowska et al., 2011), and Phytophthora (Dunne et al.,2003). Cleome spinosa is an annual herbaceous plant, and Cleome spinosa and cruciferous Brassica plants belong to Brassicales. There is no report on the biofumigation potential of Cleome spinosa. The results showed that the four doses $(0.1,0.2,0.3$ and $0.4 \mathrm{~g} / \mathrm{dish})$ of Cleome spinosa powder had inhibitory effects on Fusarium oxysporum, and the inhibition rate of $0.3 \mathrm{~g} / \mathrm{dish}$ and 0.4 $\mathrm{g} /$ dish reached $100 \%$. Furthermore, the inhibitory effect of Cleome spinosa extracts on the mycelium growth of Fusarium oxysporum was monitored. At the extract concentrations of $15,30,45$ and $60 \mathrm{mg} / \mathrm{mL}$, inhibition rates on mycelium growth were $24.52 \%, 37.38 \%, 52.36 \%$ and $59.19 \%$, and the inhibition rates of mycelial dry substances accumulation were 79.58\%, 87.67\%, 93.90\% and $98.82 \%$, respectively.

Zhong et al. (2014) used GC-MS technology to analyze the chemical constituents of volatile oil from commercial lemons. In present study, 21 volatile substances from Cleome spinosa were identified by GC/MS. The antimicrobial activity of the volatile substances showed that paeonol, linalool and theaspirane had inhibitory effects on Fusarium oxysporum, with inhibition rates of $73.9 \%, 75.9 \%$ and $80.4 \%$, respectively. This is the first study to report that paeonol, linalool and theaspirane are the main components responsible for antimicrobial activity. The fumigation effect of Cleome spinosa on Fusarium oxysporummay be the synergistic result of multiple substances. The findings are of great significance for the further application of Cleome spinosa in the future.

The tissue of Brassica plants possesses massive glucosinolates (GSLs) with not high activity. However, during the decay process, these can be hydrolyzed by self-produced myrosinase to form volatile and highly antimicrobial isothiocyanates (ITCs) (Saladino et al., 2016). Thus, the number of harmful microorganisms in the soil can be reduced. Isothiocyanates similar to those in Brassica plants were not identified based on the composition of the volatile substances of Cleome spinosa, which showed that the antibacterial mechanism of Cleome spinosa is not the same as that of Brassica plants. The highest volatile component content in Cleome spinosa was paeonol, which is widely used in the medical field due to its analgesic, sedative, hypnotic, antibacterial, anti-inflammatory, anti-oxidative, and blood pressurelowering properties. For obtaining novel compounds with significant antifungal properties, a series of paeonol derivatives linked with a 1,2,3-triazole moiety have been investigated (Jiang et al., 2017). One of the chemical components of Centaurea baseri is theaspirane, which can inhibit fungal growth (Köse et al., 2016).

Botanical pesticides have attracted increasing attention worldwide because of their low toxicity, low residue, and lack of pollution; in addition, they meet the requirements of modern environmental protection and human health. Biological fumigation using Brassica plants has been carried out, and isothiocyanate compounds are the focus of international attention. Although this experiment did not include isothiocyanates, the results are innovative and have antimicrobial implications.

Conclusion: The extracts of Cleome spinosa had inhibitory effect on mycelium growth and dry weight, and as the concentration of the Cleome spinosa extract increased, the inhibitory effects also increased. Twentyone components were identified by GC-MS, including heterocyclic compounds, alcohol, chromene, ester, acid and long chain alkanes. The results showed that paeonol, linalool and theaspirane had inhibitory effects on Fusarium oxysporum, with inhibition rates of $73.9 \%$, $75.9 \%$ and $80.4 \%$, respectively.

Acknowledgements: The present work was supported by the National Natural Science Foundation of China (31171792), the Key Projects of the Heilongjiang Natural Science Foundation (ZD2016003), and the University Nursing Program for Young Scholars with Creative Talents in Heilongjiang Province (UNPYSCT-2016146).

\section{REFERENCES}

Albarello, N., C. Simotilde, E.S. Gurgel, T.C.D. Castro, C.R.M. Gayer and M.G.P. Coelho, (2013). Antiinflammatory and antinociceptive activity of field-growth plants and tissue culture of Cleome spinosa (Jacq.) in mice. J Med Plants Res., 7(16): 1043-1049.

Collins, D.O., W.F. Reynolds and P.B. Reese, (2004). New cembranes from Cleome spinosa. J. Nat. Prod., 67(2): 179-183.

Duncan, D.B. (1955). Multiple range and multiple F tests. Biometric. 11(1): 1-42.

Dunne, C.P., B. Dell and J.H.G.E. St., (2003). The effect of biofumigantson the vegetative growth of five Phytophthora species in vitro. Acta Hortic., 602: 45-51.

El-Sharkawy, E.E.S., M.Y. Abdalla., and A.O. El-Shemy, (2016). Effect of some resistance chemical 
inducers on incidence of cucumber fusarium wilt caused by Fusarium oxysporum f. sp cucumerinum. Egypt J Biol Pest Co., 26(1):1-6.

Guo, H., X. Zhao, E.N. Rosskopf, F.D. Gioia, and, D.H. Mcnear, (2018). Impacts of anaerobic soil disinfestation and chemical fumigation on soil microbial communities in field tomato production system. Appl Soil Ecol., 126: 165173.

Henderson, D.R., E. Riga, R.A. Ramirez, J. Wilson and W.E. Snyder, (2009). Mustard biofumigation disrupts biological control by Steinernema spp. Nematodes in the soil. Biol Control, 48(3): 316322.

Jiang, Y., K. Wu, X. Tan, D. Zhang, and W. Zhang, (2017). [bmim] PF6 /KOH: A recyclable catalytic system for an azide-arylacetaldehyde [3 + 2] cycloaddition. J Chem Res, 41(11): 631635.

Köse Y.B., G. İşcan, F. Göger, G. Akalın, B. Demirci and K.H. Başer, (2016). Chemical composition and biological activity of centaurea baseri: New Species from Turkey. Chem Biodivers, 13(10): 6-10.

Krakowska, A., W. Reczyński and B. Muszyńska, (2016). Optimization of the liquid culture medium composition to obtain the mycelium of agaricus bisporus rich in essential minerals. Biological Trace Element Research. Biol Trace Elem Res, 173(1): 231-240.

Li, R., Z.Z. Shen, L. Sun, R.F. Zhang, L. Fu, X.H. Deng and Q. Shen, (2016). Novel soil fumigation method for suppressing cucumber Fusarium, wilt disease associated with soil microflora alterations. Appl Soil Ecol, 101: 28-36.

Meng, X., S. Liao, X.Y. Wang, S.X. Wang, X.F. Zhao, P. Jia, W.J. Pei, X.P. Zheng and X.H. Zheng, (2014). Reversing p-glycoprotein-mediated multidrug resistance in vitro by alpha-asarone and beta-asarone, bioactive cis-trans isomers from acorus tatarinowii. Biotechnol Lett, 36(4): 685.

Mercier, J., and J. Jiménez, (2009). Demonstration of the biofumigation activity of Muscodor albus against Rhizoctonia solani in soil and potting mix. BioControl, 54(6): 797-805.

Motisi, N., S. Poggi, J. Filipe, P. Lucas, T. Doré, F. Montfort, C. Gilligan, and D. Bailey, (2013). Epidemiological analysis of the effects of biofumigation for biological control of root rot in sugar beet. Plant Pathology, 62(1): 69-78.

Njoroge, S.M.C., M.B. Riley and A.P. Keinath, (2008). Effect of incorporation of brassica spp. residues on population densities of soilborne microorganisms and on damping-off and fusarium wilt of watermelon. Plant Dis, 92(2): 287-294.

Papadopoulos, A. and P. Alderson, (2010). A new method for collecting isothiocyanates released from plant residues incorporated in soil. Ann Appl Biol, 151(1): 61-65.

Raza, W., N. Ling, R.F. Zhang, Q.W. Huang, Y.C. Xu and Q. Shen, (2016). Success evaluation of the biological control of Fusarium wilts of cucumber, banana, and tomato since 2000 and future research strategies. Crit. Rev. Biotechnol. 37(2): 1-11.

Richard, M., (2001). Glucosinolates-bioc, hemistry, genetics and biological activity. Plant Growth Regul, 34: 91-103.

Saladino, F., K. Bordin, F. Luciano, M. Franzón, J. Mañes and G. Meca, (2016). Antimicrobial activity of the glucosinolates. In, pp. 1-26.

Silva, A.P.S., L.C.N. Silva, C.S.M. Fonseca, J.M. Araújo, M.T.S. Correia, M.S. Cavalcanti and V.L.M. Lima, (2016a). Antimicrobial activity and phytochemical analysis of organic extracts from Cleome spinosa Jaqc. Front Microbiol., 7(13): 963.

Silva, A.S.D., L.N.D. Silva, C.M.D. Fonseca, J.M. Araújo, M.D.S. Correia, M.D.S. Cavalcanti, (2016). Comparative analysis of combinatory effects of organic extracts from Cleome spinosa jaqc and oxacilin against staphylococcus aureus. Planta Med, 82(S01): S1-S381.

Spanggaard, B., H.H. Huss and J. Bresciani, (2006). Morphoogy of ichthyophonus hoferi assessed by light and scanning electron microscopy. J Fish Dis, 18(6): 567-577.

Sun, L., S. Song, L. Fu, X. Deng, D. Wang, X. Liang, L. Rong and Q. Shen, (2015). Exploring a soil fumigation strategy based on ammonium bicarbonate to control Fusarium wilts of cucurbits. Crop Prot, 70: 53-60

Szczygłowska, M., A. Piekarska, P. Konieczka, and J. Namieśnik, (2011). Use of Brassica plants in the phytoremediation and biofumigation processes. In J Mol Sci, 12(11): 7760-7771.

Wang, Q.J., Y. Ma, H. Yang and Z.Z. Chang, (2014). Effect of biofumigation and chemical fumigation on soil micro bialcommunity structure and control of pepper Phytophthora blight. World J Microbiol Biotechnol, 30(2): 507-518.

Yin, D.T., L. Wang, J.R. Sun, F.Y. Yin, Q.T. Yan, R.L. Shen, G. He and J.X. Gao, (2010). Association of the promoter methylation and protein expression of fragile histidine triad (FHIT) gene with the progression of differentiated thyroid carcinoma. Int J Clin Exp Patho, 3(5): 482-491.

Zhang, D., H. Zheng, Z.B. Ren, C. Zhai, G.Q. Shen, Z.X. Mao, P.J. Wang and X.Y. He, (2015). Effects of 
forest type and urbanization on carbon storage of urban forests in Changchun, northeast China. Chinese Geogr Sci, 25(2): 147-158.

Zhang, X.Z., R.N. Sa, J.Y. Gao, C.L. Wang, D.W. Liu and Y.J. Zhang, (2020). Preventive effect of vermicompost against cucumber fusarium wilt and improvement of cucumber growth and soil properties. Int J Agrc Biol., 23(3):515-521.

Zhang, Y.J., Z.J. Pu, Z.W. Qin, X.Y. Zhou, D. Liu, L.T. Dai and W.B. Wang, (2012). A study on the overwintering of cucumber Downy Mildew
Oospores in China. J Phytopathol, 160(9): 469474.

Zhong, S.Q., J.N. Ren, D.W. Chen, S.Y. Pan, K.X. Wang, S.Z. Yang and G. Fan, (2014). Free and bound volatile compounds in juice and peel of Eureka lemon. Food Sci Technol Res, 20(1): 167-174.

Zou, C.L., L.M. Sang, Z.J. Gai, Y.B. Wang and C.F. Li, (2018). Morphological and physiological responses of sugar beet to alkaline stress. Sugar Tech, 20(2): 202-211. 